\title{
Case Studies of Fatigue Life Improvement Using Low Plasticity Burnishing in Gas Turbine Engine Applications
}

\author{
Paul S. Prevéy \\ (pprevev@lambda-research.com) \\ Lambda Research \\ 5521 Fair Lane \\ Cincinnati, $\mathrm{OH} 45227$ \\ Michael Shepard \\ (Michael.Shepard@wpafb.af.mil) \\ Wright Patterson AFB \\ 2230 Tenth St., Ste. 1 \\ WPAFB, OH 45433-7817
}

\author{
Ravi A. Ravindranath \\ (RavindranaRA@navair.navv.mil) \\ NAVAIR, 22195 Elmer Road \\ Bldg: 106, Room: 202-G \\ Patuxent River, MD 20670-1534 \\ Timothy Gabb \\ (timothy.gabb@lerc.nasa.gov) \\ NASA Glenn Research Center \\ 21000 Brookpark, Bldg. 49, Room 231 \\ Cleveland, $\mathrm{OH}$ 44135-3191
}

\begin{abstract}
Surface enhancement technologies such as shot peening, laser shock peening (LSP), and low plasticity burnishing (LPB) can provide substantial fatigue life improvement. However, to be effective, the compressive residual stresses that increase fatigue strength must be retained in service. For successful integration into turbine design, the process must be affordable and compatible with the manufacturing environment. LPB provides thermally stable compression of comparable magnitude and even greater depth than other methods, and can be performed in conventional machine shop environments on CNC machine tools. LPB provides a means to extend the fatigue lives of both new and legacy aircraft engines and ground-based turbines. Improving fatigue performance by introducing deep stable layers of compressive residual stress avoids the generally cost prohibitive alternative of modifying either material or design.
\end{abstract}

The x-ray diffraction based background studies of thermal and mechanical stability of surface enhancement techniques are briefly reviewed, demonstrating the importance of minimizing cold work. The LPB process, tooling, and control systems are described. An overview of current research programs conducted for engine OEMs and the military to apply LPB to a variety of engine and aging aircraft components are presented. Fatigue performance and residual stress data developed to date for several case studies are presented including:

- The effect of LPB on the fatigue performance of the nickel based super alloy IN718, showing the fatigue benefit of thermal stability at engine temperatures.

- An order of magnitude improvement in damage tolerance of LPB processed Ti-6-4 fan blade leading edges.

- Elimination of the fretting fatigue debit for Ti-6-4 with prior LPB.

- Corrosion fatigue mitigation with LPB in Carpenter 450 steel.

- Damage tolerance improvement in 17-4PH steel.

Where appropriate, the performance of LPB is compared to conventional shot peening after exposure to engine operating temperatures.

\section{INTRODUCTION}

LPB is a new method of surface enhancement [1-4 ] that provides deep stable surface compressive residual stresses with little cold work for improved fatigue, fretting fatigue, and stress corrosion performance even at elevated temperatures where compression from shot peening relaxes.[5] LPB surface treatment is applied using conventional multi-axis CNC machine tools for unprecedented control of the residual stress distribution developed through modification of the pressure, feed, and tool characteristics. The resulting deep layer of compressive residual stress has been shown to improve high cycle fatigue (HCF) and low cycle fatigue (LCF) performance and foreign object damage (FOD) tolerance.[6-7] Achieving deep compression with low cold work $(<5 \%)$ reduces relaxation of the protective compressive layer either thermally during exposures at service temperatures, or mechanically due to overload or impact, as in FOD. Both thermal and mechanical relaxation occur in the 
cold worked surfaces produced by conventional shot peening of titanium[7] and nickel alloys. [5,6]

The LPB tooling and process are described and the protocol for use of LPB in fatigue-critical design is presented. LPB has been applied to titanium, iron and nickel based aero-turbine engine alloys to improve damage tolerance in compressor sections by an order of magnitude and to improve high and low cycle fatigue performance in hot turbine sections. In addition to turbine engine components, this novel technology has been shown to have potential applications in aging aircraft structures, nuclear wastematerial containers, biomedical implants and welded joints. This paper attempts to present a brief overview of the fatigue and damage tolerance improvement achievable with LPB in aero engine components.

\section{NOMENCLATURE \\ LPB - Low Plasticity Burnishing \\ $\mathrm{SP}$ - Shot peening \\ HCF - High Cycle Fatigue \\ EDM - Electrical-discharge machining \\ FOD - Foreign Object Damage \\ CW - Cold work \\ RS - Residual Stress \\ $\mathrm{XRD}$ - X-ray diffraction}

\section{The Low Plasticity Burnishing (LPB) Process:}

LPB is a method of CNC controlled burnishing designed to produce a deep layer of highly compressive residual stress with a minimum amount of cold working, or plastic deformation. Residual compressive stresses approaching the material yield strength are developed using a series of passes of a freely rotating ball tool producing an accumulated plastic strain, or cold work, level of less than 3 to $5 \%$. In contrast, the multiple random shot impacts of conventional shot peening produce cold work levels ranging from $20 \%$ to over $100 \%$, leaving a severely deformed surface layer with a high dislocation density that adversely affects the thermal and mechanical stability of the compressive layer.[5,7]

Unlike LPB, conventional roller and ball burnishing utilize a hard wheel tool or fixed lubricated ball pressed into the surface of an axisymmetric work piece with sufficient force to deform the near surface layers, usually in a lathe. Burnishing is performed with multiple passes, usually under increasing load, to improve surface finish and to deliberately cold work the surface. Roller and ball burnishing have been studied in Russia and Japan, and were applied most extensively in the USSR in the 1970's. Various burnishing methods are used, particularly in Eastern Europe to improve fatigue life. Improvements in HCF, corrosion-fatigue, and stress corrosion crackin $g$ are documented, with fatigue strength enhancement attributed to improved finish, the development of a compressive surface layer, and the increased yield strength of the cold worked surface.[8-13] Optimum forces and rolling parameters were established to minimize roughness and/or maximize surface hardening.[14-17] Analytical models to predict the residual stresses have been attempted in England[18] and France.[19] "Deep rolling" employs either roller tools or a partially hydrostatically supported burnishing ball, but differs from LPB in the use of higher loads and cold work levels, tool design, and control. X-ray diffraction line broadening and microhardness reveal that deep rolling produces even more cold work than shot peening.[20-22]

The basic LPB tool is comprised of a ball that is supported in a spherical hydrostatic bearing as $\mathbf{s}$ hown in Figure 1. The tool can be held in any CNC lathe or mill. The machine tool coolant is used to pressurize the bearing with a continuous flow of fluid to support the ball. The ball does not contact the bearing seat, even under load. The ball is loaded normal to the surface of a component with a hydraulic cylinder that is in the body of the tool. LPB can be performed in conjurnction with chip forming machining operations in the same CNC machine tool.

The ball rolls across the surface of a component in a pattern defined in the $\mathrm{CNC}$ code, as in any maclhining operation. The tool path and normal pressure applied are designed to create a distribution of compressive residual stress. The form of the distribution is designed to counter applied stresses and optimize fatig ue or stress corrosion performance. Since there is no shear being applied to the ball, it is free to roll in any direction. As the ball rolls over the component, the pressure from the ball causes plastic deformation to occur in the surface of the material under the ball. Since the bulk of the material constrains the deformed area, the deformed zone is left in compression after the ball passes. No material is reno ved during the proces $\mathbf{s}$. The surface is permanently displaced inward by only a few ten-thousandths of an inch (0.002-0.015 mm (O.00010.0006 in.). LPB smoothes surface asperities leav ing an improved surface finish that can be better than $S \mu$ in., RA. Dual sided LPB processing of a $17-4 \mathrm{PH}$ compressor blade with caliper tooling and a larger finished Ti-6-4 blade are shown in Figures $2 \mathrm{a}$ and $2 \mathrm{~b}$. 


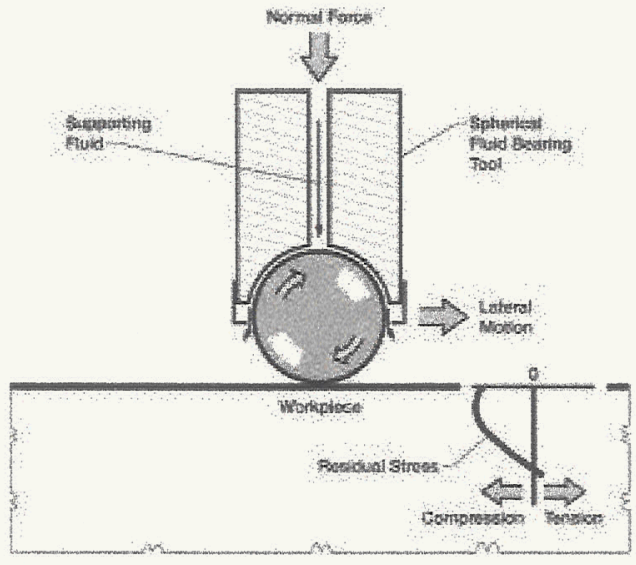

Figure 1 - LPB Schematic

\section{X-ray Diffraction, Residual Stress and Cold Work Determination}

XRD residual stress measurements were made employing a $\sin ^{2} \psi$ technique and the diffraction of the appropriate radiation. It was first verified that the lattice spacing was a linear function of $\sin ^{2} \psi$ as required for the plane stress linear elastic residual stress model. [23-26]

Measurements were made as a function of depth by incremental electropolishing to the final depth shown. The residual stress measurements were corrected for both the penetration of the radiation into the subsurface stress gradient [27] and for stress relaxation caused by layer removal. [28]

The value of the $x$-ray elastic constants required to calculate the macroscopic residual stress from the crystal lattice strain were determined in accordance with ASTM E1426-91. [29] Systematic errors were monitored per ASTM specification E915.

The $K \alpha_{1}$ peak breadth was calculated from the Pearson VII function fit used for peak location during macroscopic stress measurement. [30] The percent cold work was calculated using an empirical relationship established between the material cold working (true plastic strain) and the $\mathrm{K} \alpha_{1}$ line broadening [31] The percent cold work is a scalar quantity, taken to be the true plastic strain necessary to produce the diffraction peak width measured based on the empirical relationship.

\section{Thermal Stability of LPB Residual Stress Distributions:}

Surface enhancement methods introduce a layer of compression on the surface of a component to enhance HCF performance or to mitigate the fatigue or stress corrosion debit caused by pitting corrosion, FOD, or other surface damage. Historically, shot peening (SP) has been widely used to significantly improve HCF performance. However, the heavy surface cold work, surface roughness, and potential surface damage associated with SP limit the range of application. The high degree of cold work produced by SP leads to both thermal and mechanical relaxation [5,7], and may leave the surfaces more prone to corrosion related damage. In contrast, LPB inherently pro duces little cold work in developing a deep layer high compression. LPB processing parameters (including ball size, type, applied pressure/vertical displacement, lateral velocity, feed, work piece mechanical properties, etc.,) are developed for a given material and geometry using x-ray diffraction measurement of residual stress and cold work distributions. Discussion of the LPB parameter development is beyond the scope of this paper.

Depending on the LPB process parameters and material characteristics, the residual stress state and the corresponding percent cold work (both depth profile and surface distribution) vary as functions of position. A large database has been developed to document these distributions for a variety of stru ctural engineering materials of interest to aerospace, automotive, nuclear, and biomedical applications. A typical set of residual stress and corresponding percent cold work depth profiles for IN718 are shown in Figure 3. The effects of thermal exposure to $525^{\circ} \mathrm{C}$ and $600^{\circ} \mathrm{C}$ on the residual stress profiles are included. For the sake of comparison, typical results from shot peened (SP) surfaces given the same thermal exposure are included in these figures. Similar thermal relaxation studies have been conducted in many other material systems of interest to the turbine engine industry. Figure 4 shows the relaxation effects in LPB processed Ti-6Al-4V after exposure to $425^{\circ} \mathrm{C}$.

In the IN718 example, it is seen that the LPB process achieved compression to a depth exceeding 1 $\mathrm{mm}(0.04 \mathrm{in})$, reaching a maximum of nominally -1100 $\mathrm{MPa}(-159.6 \mathrm{ksi})$ at nominally $250 \mu \mathrm{m}(0.01 \mathrm{in})$ with less than $5 \%$ cold work through the compressive zone. In contrast, SP produced a depth of compression less than $250 \mu \mathrm{m}$ ( $0.01 \mathrm{in}$.) with over $60 \%$ cold work on the surface. Retention of surface compression is imp ortant in HCF were suppression of surface fatigue initiation typically governs life. After 100 hours of exposure to $525^{\circ} \mathrm{C}$, the LPB processed material showed very little relaxation of residual stress at the surface, while the SP processed material lost surface compression from over $-800 \mathrm{MPa}(-116 \mathrm{ksi})$ to under $-100 \mathrm{MPa}(14.5 \mathrm{ksi})$. This stress relaxation is attributed to the heavy cold work experienced by SP, leading to rapid recovery and stress relaxation during thermal exposure.[5] Similar thermal relaxation data have been obtained for LPB and $\mathbf{S P}$ in a 
number of $\mathrm{Ti}, \mathrm{Fe}$ and $\mathrm{Al}$ alloys and similar response to thermal exposure have been observed.[6,7] Using larger tools and higher pressures, compression up to 8 $\mathrm{mm}$ (0.3 in.) depth has recently been achieved in stainless steel welded plates.

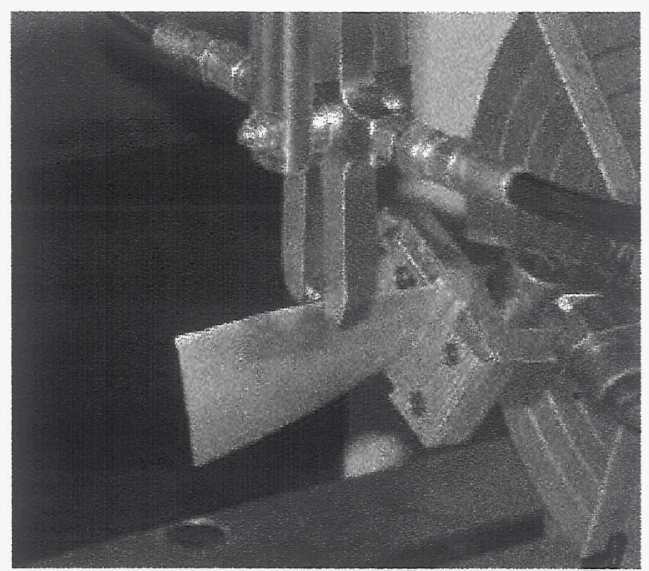

(a)

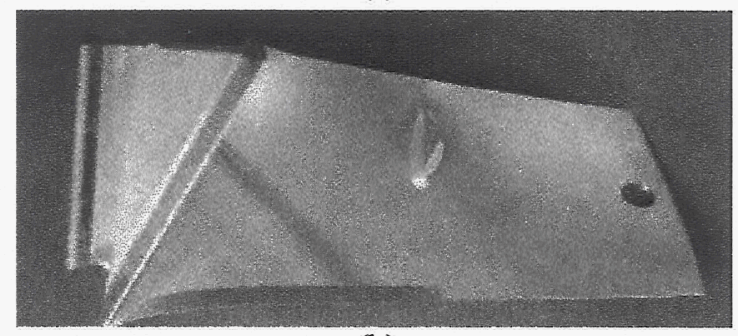

(b)

Figure 2 (a) 17-4PH compressor blade being processed on the leading edge (LE) with an LPB caliper tool to improve FOD tolerance; (b) Ti-6-4 fan blade LPB processed along the lower LE. The hole near tip was made for HCF testing in cantilever bending (see Figure 8).

\section{Fatigue Testing:}

HCF tests were conducted on specially designed test specimens to simulate the service conditions of the components. For this purpose, thick section $(9.5$ mm (0.37 in.)) specimens with trapezoidal cross-section (designed for testing highly compressive surfaces) or a blade-edge feature cross-section were tested under a four-point bending load with the capability to vary applied R-ratios $\left(\sigma_{\min } / \sigma_{\max }\right)$. Crack propagation for the thick section samples was from the surface through the depth of the compressive layer. Blade-edge samples were processed to produce through-thickness compression and tested with the crack propagating from the edge, perpendicular to the processed surfaces. In most instances, an R-ratio of 0.1 was used to simulate the high mean load common to rotating turbine components. HCF tests were run at a frequency of $30 \mathrm{~Hz}$ to either failure or a run-out condition of $2.5 \times 10^{6}$ cycles.

Engine operating conditions were simulated in several ways. For example, typical FOD conditions were simulated by either pressing an indentation, machining a notch, or using electro-discharge machining (EDM). To simulate exposure to engine temperatures, specimens were typically exposed to engine operating temperatures for a fixed time before HCF testing to allow thermal relaxation. Active corrosion was simulated by wrapping pads soaked in corroding media around the samples for the duration of the test. Fretting fatigue was simulated using a specially designed "bridge" fretting fixture with variable fretting normal loads (Figure 13).

\section{Effect of LPB on HCF Performance and FOD Tolerance:}

The thick section HCF results for IN718 presented in Figure 5 show a substantial increase in the HCF endurance limit, or fatigue strength at $2 \times 10^{6}$ cycles for LPB over shot peening for either $525^{\circ} \mathrm{C}$ or $600^{\circ} \mathrm{C}$ exposure for $100 \mathrm{hrs}$. The similar fatigue performance for shot peening followed by either $525^{\circ} \mathrm{C}$ or $600^{\circ} \mathrm{C}$ exposure is attributed to the near uniform relaxation of the surface compression seen in Figure 3 after exposure to either temperature. The endurance limit is typically associated with surface residual compression governing the initiation of fatigue cracks while fatigue strength in the finite life regime is dominated by crack growth through the depth of the compressive layer left by surface enhancement.

The difference in the ability of the two surface enhancement methods to resist FOD either in the form of a single indentation or a sharp notch is shown in Figure 6. The endurance limit is reduced from nominally 700 to $300 \mathrm{MPa}$ (101. to $43.5 \mathrm{ksi}$ ) by either form of damage. The deep compressive layer produced by LPB is more effective in retarding crack growth, even after thermal exposure, because of the minimal thermal stress relaxation and the greater depth of the compressive layer. Although considerable scatter is evident in the $\mathrm{LPB}+\mathrm{FOD}$ data (which is attributed to variability in the FOD damage) all of the specimens treated by LPB have fatigue strengths and lives superior to that of shot peening even without FOD. 


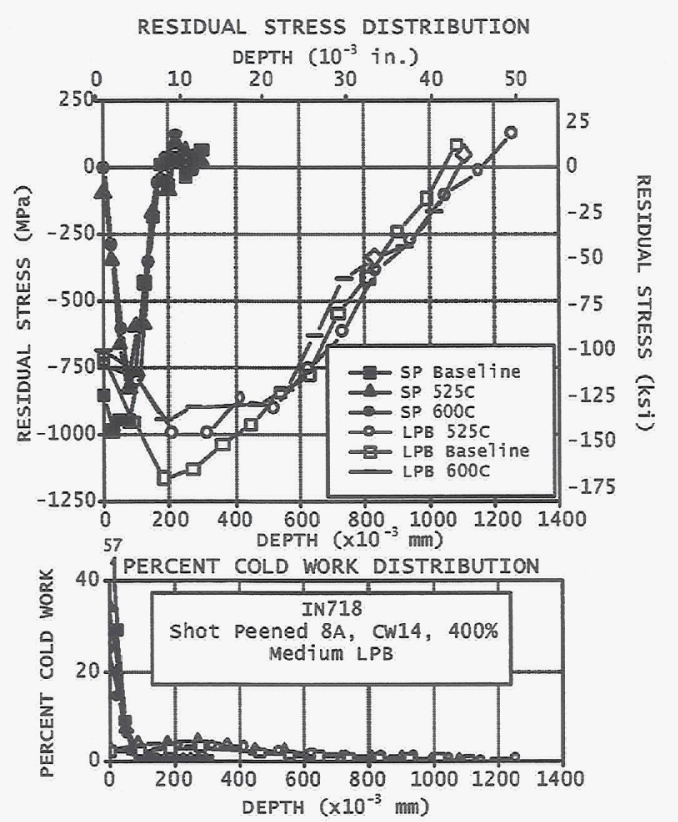

Figure 3 - Residual Stress and cold work depth profiles for IN718 before and after exposure to service temperature of $525^{\circ}$ and $600^{\circ} \mathrm{C}$ for $100 \mathrm{hrs}$.

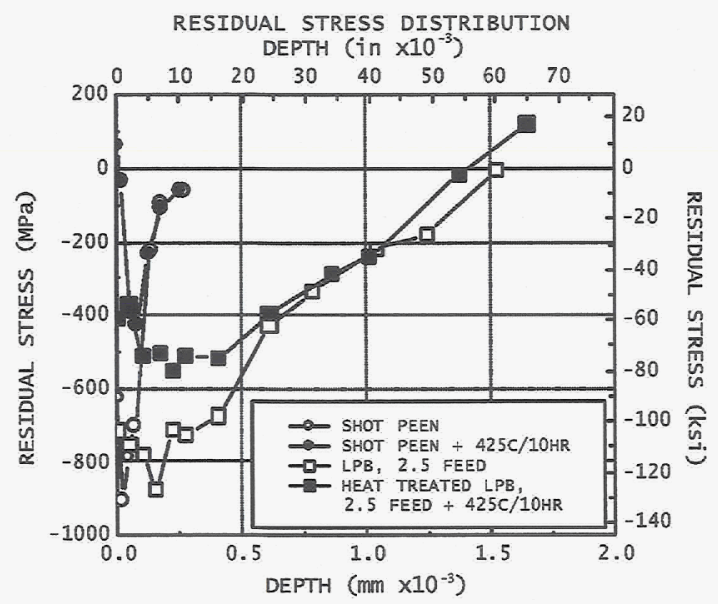

Figure 4-Thermal relaxation of shot peened (8A, $400 \%$ ) and LPB processed Ti-6Al-4V after $795^{\circ} \mathrm{F}$ $\left(425^{\circ} \mathrm{C}\right)$ for $10 \mathrm{hr}$.

HCF data for thick section Ti-6Al-4V shows similar trends in Figure 7. The HCF results presented in this figure show a $38 \%$ increase in the endurance limit for LPB (>620 MPa (>90ksi)) compared to shot peening $(\sim 448 \mathrm{MPa}(\sim 65 \mathrm{ksi}))$ after exposure to $425^{\circ} \mathrm{C}\left(795^{\circ} \mathrm{F}\right)$ for 10 hrs. The increased endurance limit after surface enhancement is generally associated with surface compression delaying the initiation of fatigue cracks at the surface. The reduced HCF strength of the highly cold worked shot peened condition is attributed to the complete loss of surface compression after even a brief elevated temperature exposure.

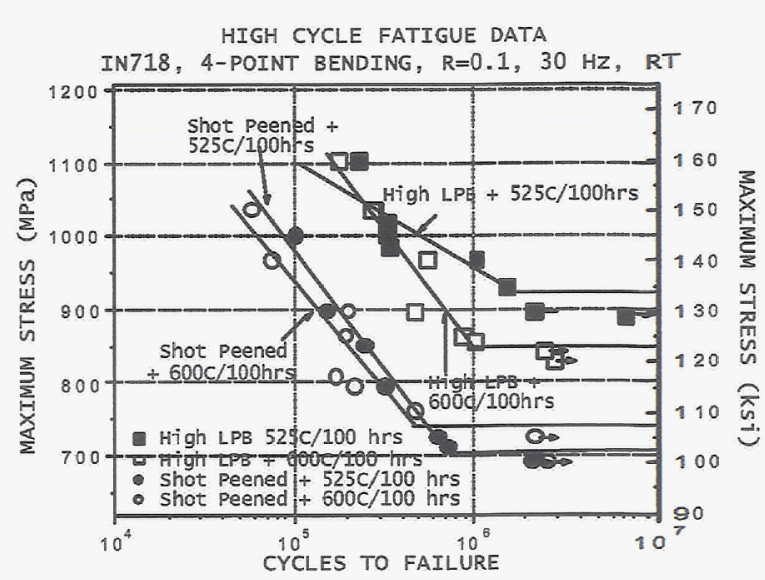

Figure 5 - High eycle fatigue performance of shot peened $(8 \mathrm{~A}, 400 \%)$ and LPB processed thick section IN7 18 after $100 \mathrm{hr}$. exposures at $525^{\circ}$ and $600^{\circ} \mathrm{C}$.

\section{Improved Damage Tolerance in Aero Engine Components:}

LSP of the leading edges of fan and compressor blades improves damage tolerance, in terms of FOD depth, by at least an oder of magnitude. The high magnitude through-thickness compression achieved by LSP retards both fatigue crack initiation and growth, but requires expensive specialized laser systems. LPB has been investigated as a means of inducing throughthickness leading edge compression for improved damage tolerance in first stage Ti-6-4 fan blades. Fatigue performace was assessed by testing actual fan blades with controlled depth simulated leading edge FOD.

To establish the appropriate depth of simulated FOD, size and location distributions of service generated FOD were documented for used blades. Service induced FOD on the leading edge ranged from $0.005 \mathrm{~mm}(0.0002 \mathrm{in}$.) to less than $0.50 \mathrm{~mm}(0.02 \mathrm{in}$.) deep. Ninety percent of FOD depths observed were less than $0.05 \mathrm{~mm}$ (0.002 in.). Blades are currently removed for re-work or replacement if FOD $0.13 \mathrm{~mm}$ $(0.005$ in.) deep is found durng inspection. Conservatively, $0.50 \mathrm{~mm}$ was chosen as the minimum depth for FOD to be induced in blades for this study. Simulated FOD $0.5 \mathrm{~mm}$ (0.02 in.) and $1.2 \mathrm{~mm}$ (0.05 in.) in depth was created by machining 60 degree "V" notches in blades in the leading edge location at which maximum stress occurred during fatigue loading. 
HIGH CYCLE FATIGUE DATA IN718, 4-POINT BENDING, $R=0.1,30 \mathrm{~Hz}$, RT

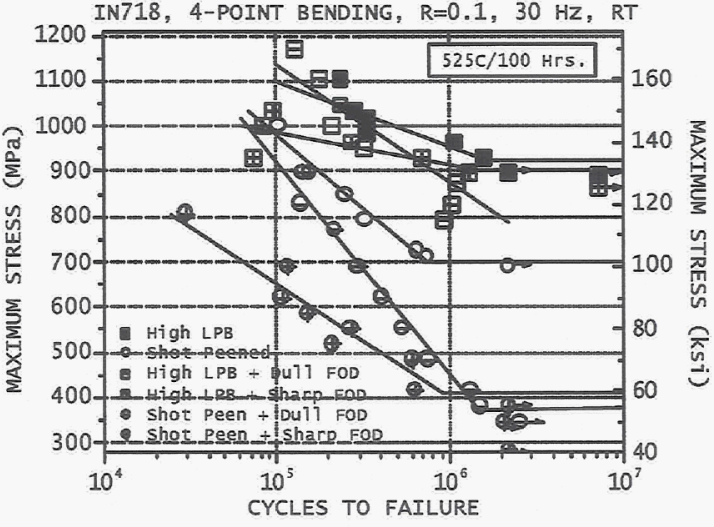

Figure 6-HCF tolerance of dull and sharp FOD after elevated temperature exposure simulating engine environments for shot peened $(8 \mathrm{~A}, 40 \%)$ and low plasticity burnished (LPB) thick section IN 718.

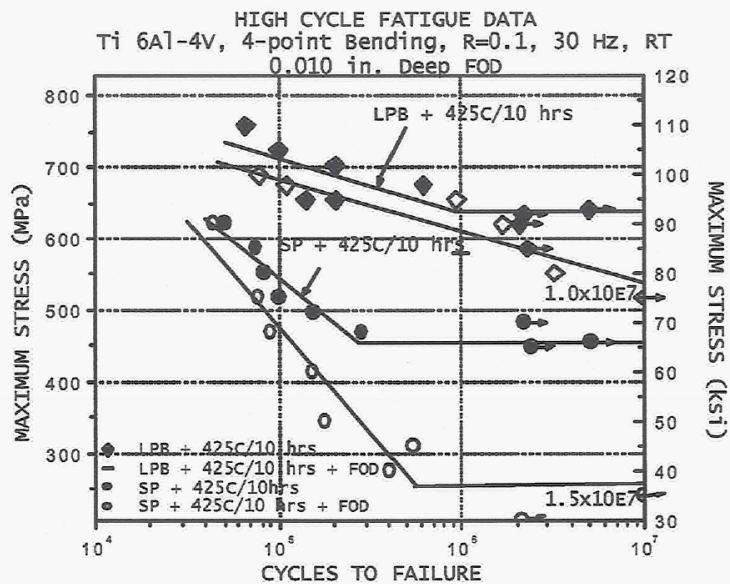

Figure 7- HCF performance of thick section Ti-6-4 after SP and LPB surface treatments with and without the presence of a $250 \mu \mathrm{m}(0.01$ in.) FOD after exposure to service temperatures.

LPB processing CNC code was designed and LPB parameters developed to create through-thickness compression of nominally $-689 \mathrm{MPa}(-100 \mathrm{ksi})$ from the blade leading edge to a nominal distance of $6.4 \mathrm{~mm}$ $(0.25 \mathrm{in}$.) chord-wise from the leading edge. The extent of the LPB zone running along the leading edge, from the mid-span damper to the platform, may be seen clearly as the region of improved surface finish in Figure $2 b$.

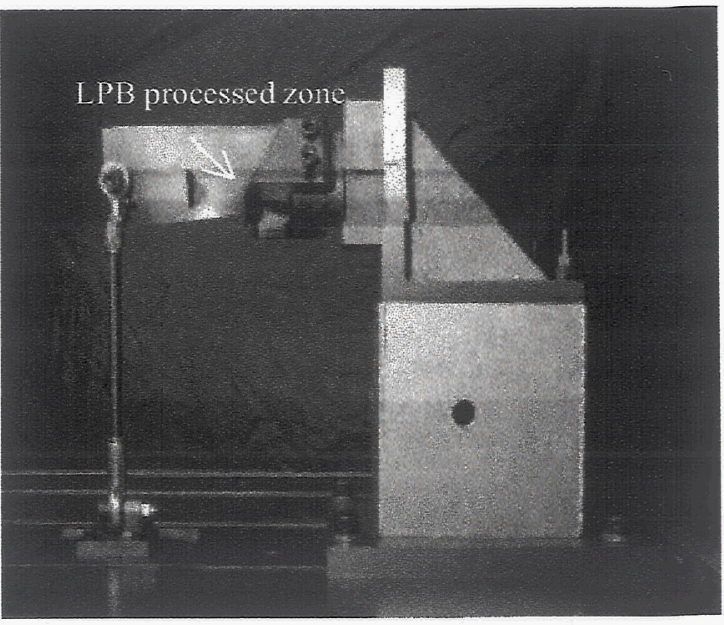

Figure 8 - Photograph showing the cantilever-loading fixture for fatigue testing of the first stage fan blade. Note the LPB patch along the (upper) leading edge of the blade.

Fatigue comparisons were made using used blades as test specimens cantilever loaded at $R=0.1$ to simulate the high mean load imposed on the leading edge during service in a rotating engine, as shown in Figure 8. The SN curves developed are shown in Figure 9. In the absence of FOD, LPB processing increased fatigue strength by nominally $207 \mathrm{MPa}(30$ ksi) over non-processed blades, and approached the material yield strength. In all but one instance, LPB processed blades tested without FOD at such high stress levels failed outside the most highly stressed LPB-processed area, usually in the dovetail region.

Introduction of $0.5 \mathrm{~mm}$ (0.02 in.) deep simulated FOD in non-LPB blades reduced the fatigue strength $65 \%$ from 689 to $241 \mathrm{MPa}$ (100 to $35 \mathrm{ksi}$ ). Introduction of the same $0.5 \mathrm{~mm}(0.02 \mathrm{in}) \mathrm{FOD}$ after LPB processing resulted in fatigue strength equal to that of non-LPB processed blades without FOD. FOD $1.27 \mathrm{~mm}$ ( $0.05 \mathrm{in}$.) deep after LPB reduced the fatigue strength to 620 $\mathrm{MPa}$ (90 ksi), only $10 \%$ less than the strength of unprocessed blades.

Similarly, Figure 10 shows the beneficial effects of LPB in mitigating HCF damage and improving FOD tolerance in a Ti-6-4 low pressure vane LPB processed to produce nominally $-689 \mathrm{MPa}(100 \mathrm{ksi})$ throughthickness compression on the loaded edge. The vanes were tested in cantilever loading conditions similar to the 


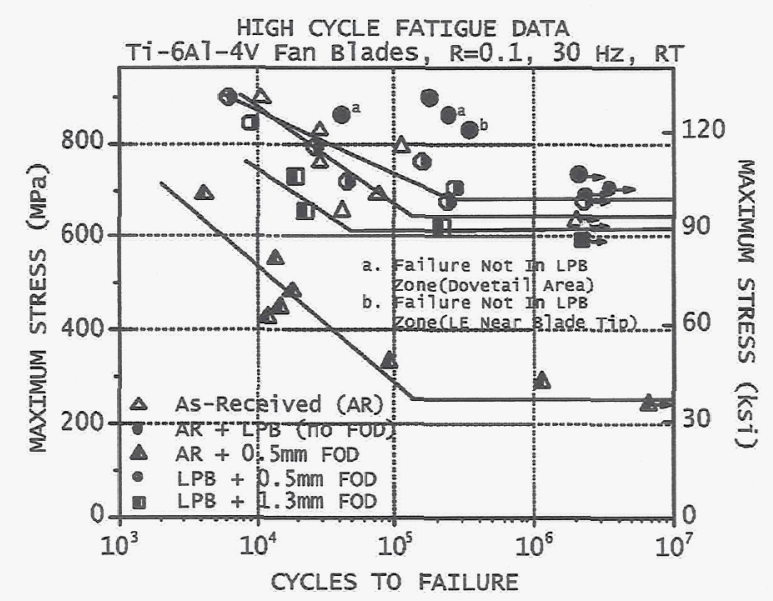

Figure 9 - Effect of LPB in mitigating HCF and FOD damage in Ti-6-4 fan blades.

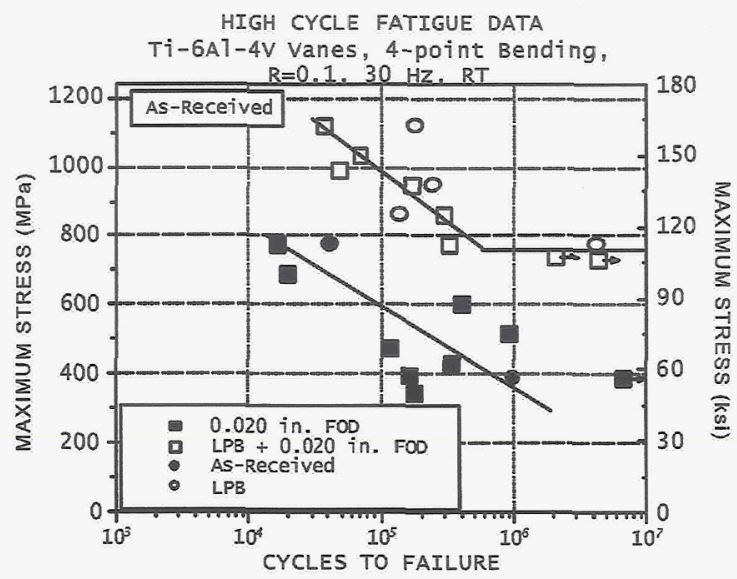

Figure 10 - Effect of LPB in mitigating HCF and FOD damage in a Ti-6-4 low pressure vane (LPV).

test methods used for the fan blades shown in Figure 8. The fatigue strength of the LPB processed vanes (even in the presence of a $0.5 \mathrm{~mm}$ (0.02 in.) FOD) approached the tensile yield strength of the material.

The high compression developed by LPB improves fatigue strength with and without FOD by retarding both crack initiation and growth. However, the benefit is most evident with surface damage present. The through-thickness compression superimposed upon the applied tensile stress shifts the mean stress toward or into compression, resulting in a higher allowed alternating stress. Fracture mechanics based fatigue life analysis using the AFGROW code confirms that for an edge crack growing in a thin plate through a zone of through-thickness compression, the endurance limit is nominally equal to the magnitude of compression present, and the depth of damage (crack) tolerated is approximately equal to the width of the zone of through-thickness compression (measured from the edge.)

Damage Tolerance Improvements in 17-4 PH Stainless Steel:

Figure 11 shows the HCF performance of thick section 17-4 PH stainless steel. In this plot, the baseline data (low-stress ground and buffed surface condition) is compared with HCF data for shot peened and LPB conditions. The base-line fatigue strength is $930 \mathrm{MPa}(135 \mathrm{ksi})$, only slightly lower than the $965 \mathrm{MPa}$ (140 ksi) strength of the shot peened condition. In contrast, LPB produced a fatigue strength (in bending) of $1240 \mathrm{MPa}$ (180 ksi), exceeding the material's tensile yield strength (1033 $\mathrm{MPa}(150 \mathrm{ksi})$ ) due to the introduction of residual compression on the order of the yield strength.

The HCF performance without LPB dropped dramatically when $0.25 \mathrm{~mm}$ (0.01 in.) deep by $0.76 \mathrm{~mm}$ ( 0.03 in.) long FOD was introduced by EDM. As seen in Figure 11, SP and the base-line fatigue strengths with FOD were only $276 \mathrm{MPa}$ (40 ksi) and $172 \mathrm{MPa}(25$ $\mathrm{ksi}$ ), respectively. With the same FOD, the fatigue strength of LPB surface treated specimens was nominally $1033 \mathrm{MPa}(150 \mathrm{ksi})$, comparable to the strength of the base-line material without FOD.

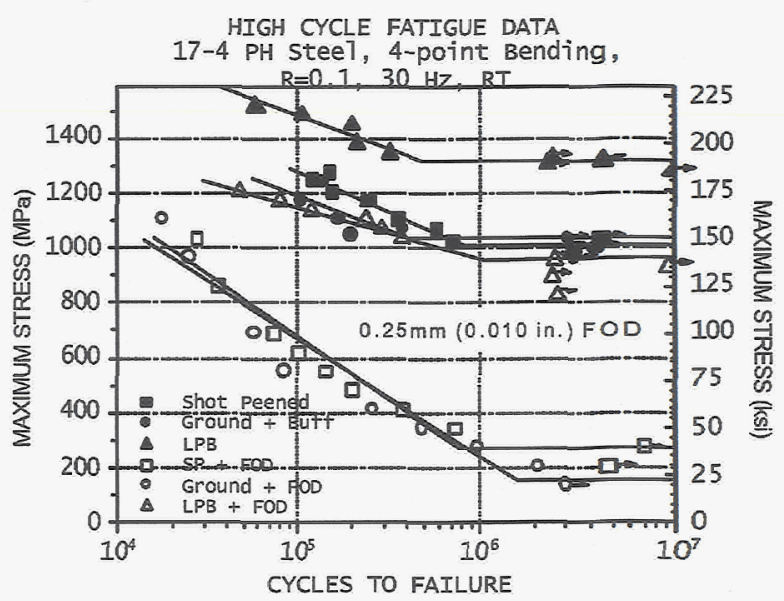

Figure 11 - HCF performance of thick-section 17-4 PH stainless steel with $0.25 \mathrm{~mm}$ (0.010 in.) FOD for base line, shot peened and LPB surfaces.

\section{Mitigation of Corrosion Damage in Turbine Engine Alloys:}

Turbine engine components can be seriously affected by the presence of corrosion environments leading to pitting and significant debit in HCF lives. Salt spray corrosion pits are a common fatigue crack initiation site in ferritic stainless steels. Salt corrosion pitting can result from exposure to a marine atmosphere 
or steam turbine environments. Pitting depths, and the corresponding stress intensity factor, depend upon the time of exposure, temperature, and the service environment of the turbine engine. Salt pit corrosion typically reduces the endurance limit to nominally half of the uncorroded value. The effects of corrosion are often further exacerbated by the presence of FOD or erosion.

The effect of active corrosion (during fatigue cycling) on HCF behavior was monitored by exposing the thick section bend specimens to a corrosive medium during fatigue tests. A chemical-free absorbent pad soaked in an acidic salt solution (3.5wt\% NaCl, $\mathrm{pH}$ 3.5) was taped to the gauge section of the specimens and sealed to prevent evaporation with a thin plastic film. All other test conditions were as described earlier for studying thick-section HCF behavior. The effects of LPB on the active corrosion fatigue performance of Custom 450 stainless steel are presented in Figure 12.

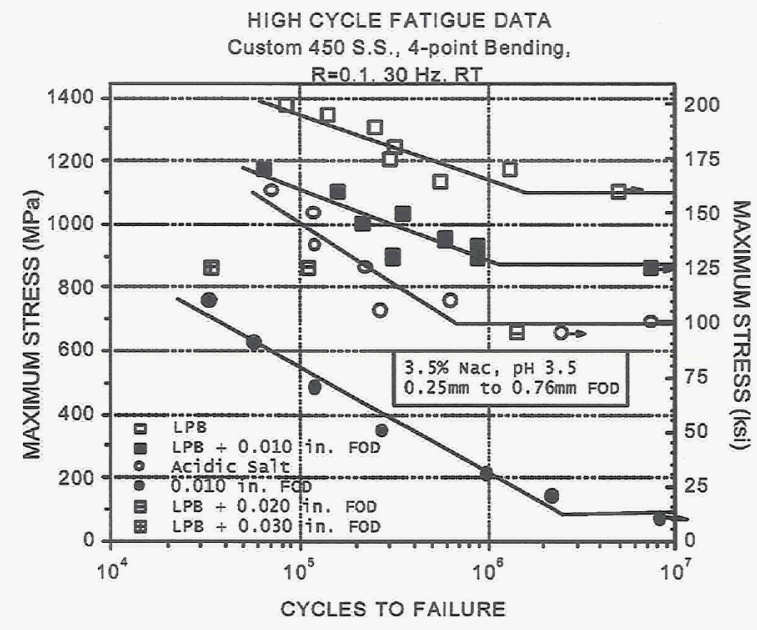

Figure 12 - Corrosion fatigue performance of Custom 450 stainless steel with FOD in acidic salt solution and FOD from $0.25 \mathrm{~mm}(0.010 \mathrm{in}$.) to $0.76 \mathrm{~mm}(0.030 \mathrm{in}$.).

The low-stress ground base-line fatigue strength, tested in acid salt solution without FOD, was nominally $689 \mathrm{MPa}(100 \mathrm{ksi})$. The base line fatigue strength with $0.25 \mathrm{~mm}(0.01 \mathrm{in}$.) FOD was only $69 \mathrm{MPa}(10 \mathrm{ksi})$. In comparison, the LPB treated samples had fatigue strengths of over $1102 \mathrm{MPa}$ (160 ksi) in the corrosive environment alone, and $861 \mathrm{MPa}(125 \mathrm{ksi})$, well above the base-line condition without FOD, with $0.25 \mathrm{~mm}$ (0.01 in.) FOD. Although full SN curves were not generated, when FOD depth was increased to $0.50 \mathrm{~mm}$ (0.02 in.) and $0.76 \mathrm{~mm}(0.03 \mathrm{in}$.), the further debit in HCF performance was minimal.
Mitigation of Fretting Fatigue Damage in Ti-6AI $-4 \mathrm{~V}$ :

Fretting damage and the resulting $\mathrm{HCF}$ performance debit can reduce the HCF strength by $50 \%$ and limit the life of turbine engine fan and compressor dovetail joints. Fretting occurs were component surfaces are pressed into physical contact under loading conditions that produce small relative movement. Shallow shear stress cracks initiated at the edges of the fretting scars can grow in mode I to failure.

Controlled fretting damage HCF tests were conducted on thick section Ti-6-4 to determine whether a deep layer of high residual compression produced by LPB could arrest the fretting induced shear cracking and prevent mode I propagation to failure, improving the fretting fatigue strength. Fretting damage was introduced into two sets of HCF samples both by prefretting the sample prior to fatigue testing (to introduce prior damage), and by fretting during testing. Fretting damage was produced by pressing two Ti-6-4 alloy cylindrical rods with a $6.3 \mathrm{~mm}(0.25 \mathrm{in}$.) diameter into the active gage surface of the fatigue specimen gage section using a bridge device to hold the rods. The rods were pressed into the fatigue specimen with a constant load of approximately $33.7 \mathrm{~N}(150 \mathrm{lbs})$ (i.e., 16.8 $\mathrm{N}$ per rod), producing a nominal contact stress of approximately $462 \mathrm{MPa}(67 \mathrm{ksi})$. The fretting fixture was instrumented with strain gages and calibrated to record the normal load during testing. Figure 13 shows a photo of the fretting fixture positioned on a fatigue specimen.

The fretting fatigue results for thick section Ti-6-4 are shown in Figure 14. Specimens were surface treated, exposed to simulated engine temperatures $\left(375^{\circ} \mathrm{C}\right.$ for $10 \mathrm{hr}$ ) and then subjected to fretting fatigue at room temperature. The fatigue strength for electropolished base-line Ti-6-4 tested at $\mathrm{R}=0.1$ in fourpoint bending is nominally $482 \mathrm{MPa}$ (70 ksi), which decreased drastically to about $172 \mathrm{MPa}(25 \mathrm{ksi})$ when subjected to fretting. Compressive residual stresses from shot peening provide significant benefit in restoring the fatigue strength to $413 \mathrm{MPa}$ ( $60 \mathrm{ksi})$, nearly the base-line strength. In comparison, LPB produced nearly full restoration at $482 \mathrm{MPa}$ (70 ksi). All but two LPB specimens tested at high stress Ievels (758 and $827 \mathrm{MPa}$ (110 and $120 \mathrm{ksi}$ )) failed outside of the LPB zone or sub-surface, with crack initiation from defects just below the compression zone, and not in the fretting scars.

\section{SUMMARY}

The life of turbine engine and power systems is limited by fatigue, FOD, corrosion fatigue and fretting fatigue. Even small FOD, corrosion pits, or other surface damage can nucleate fatigue failures with 
catastrophic consequences. The cost of inspection and maintenance required to avoid fatigue failures is estimated in the billions of dollars annually. Design or material changes generally provide only limited fatigue improvement at huge cost. Surface enhancement by LPB provides a thermally stable deep layer of compressive residual stress that can dramatically improve fatigue performance of turbine alloys without altering either alloy or design.

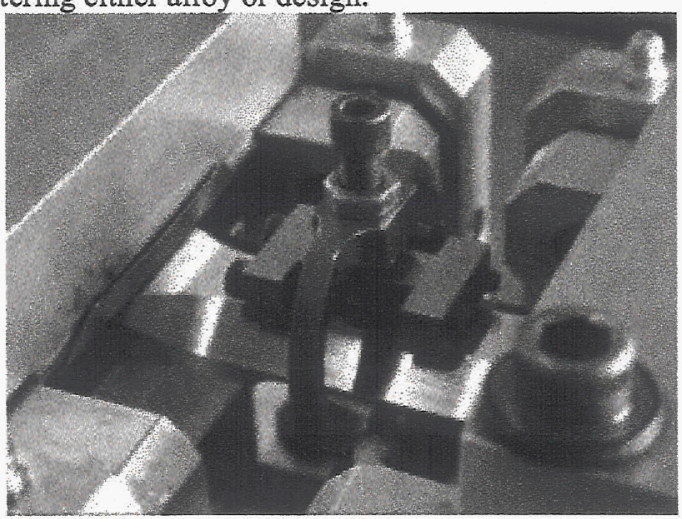

Figure 13 - Photograph of the fretting fixture showing the top two fretting rods clamped onto the top surface of the thick section HCF specimen.

HIGH CYCLE FATIGUE DATA

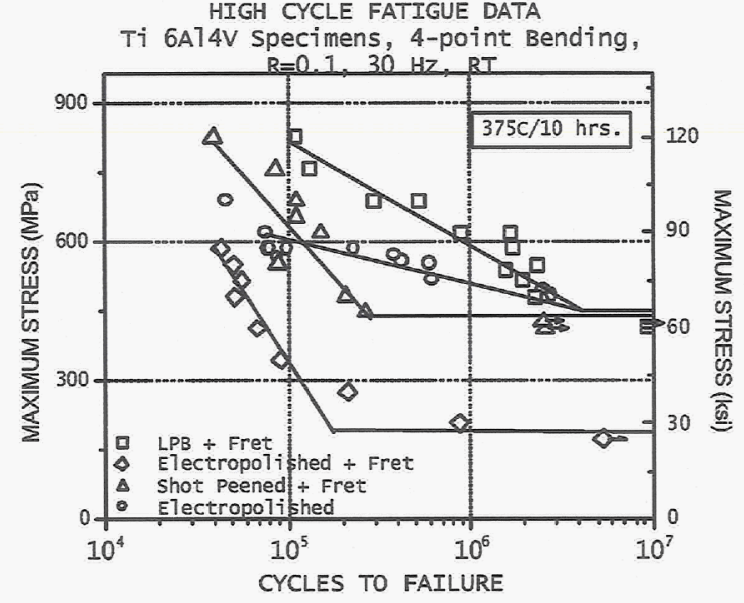

Figure 14 - Ti-6Al-4V fretting fatigue data for shot peened and LPB surface treatments.

As summarized in this paper, the deep compression from LPB has been shown to resist thermal relaxation at turbine operating temperatures far better than conventional shot peening. The deep layer of compression has been shown to completely mitigate FOD up to $0.25 \mathrm{~mm}(0.01 \mathrm{in}$.) deep in Ti-6-4, IN718 and 17-4PH. Damage $1.27 \mathrm{~mm}$ (0.05 in.) deep can be tolerated in Ti- $6-4$ blade edges. The corrosion fatigue strength of Carpenter 450 and fretting fatigue performance of Ti-6-4 can be substantially improved. Performance studies of other alloys are in process with comparable initial results.

LPB can be performed on conventional CNC machine tools in a conventional machine shop environment either in original manufacturing or during overhaul and repair. Residual stress distributions designed to cancel applied tension can be induced into the component surface to provide optimal fatigue performance at costs comparable to conventional machining. LPB offers the turbine designer a means, in addition to material selection and design, to improve turbine component performance and life at reduced operating costs.

\section{ACKNOWLEDGMENTS}

Support for the development of the data presented here was provided under SBIR programs through NASA, Glenn Research Center, under the direction of Dr. Timothy Gabb; Wright Patterson AFB Materials Lab under the direction of Mr. Michael Shepard, the US Navy, NAVAIR, under the direction of Mr. Ravi Ravindranath, and with internal research support from Lambda Research. The financial support and technical guidance provided is gratefully acknowledged and much appreciated.

\section{REFERENCES}

1. U.S. Patents $5,826,453$ (Oct. 1998), 6,415,486 B1 (Jul. 2002) other US and foreign patents pending.

2. "Low Plasticity Burnishing", NASA Tech Briefs, Aug. 2002, pg. 50.

3. "Longer Life with Low-Plasticity Burnishing", Manufacturing Engineering, SME, ed. Brian Hogan, Dec. 2001, pg. 34-38.

4. T. Gabb, J. Telesman, P. Kantzos, P. Prevéy, "Surface Enhancement of Metallic Materials", Advanced Materials \& Processes, ASM, ed. Peg Hunt, Jan. 2002, pg. 69-72.

5. P. Prevéy, "The Effect of Cold Work on the Thermal Stability of Residual Compression in Surface Enhanced TN718", Proc. 20 th $A S M$ Materials Solutions Conf., St. Louis, MO, Oct. 1012, 2000.

6. P. Prevéy, et al, "FOD Resistance and Fatigue Crack Arrest in Low Plasticity Burnished IN718", Proc. $5^{\text {th }}$ National HCF Conf., 2000.

7. P. Prevéy, et al, "The Effect of Low Plasticity Burnishing on the HCF Performance and FOD Resistance of Ti-6Al-4V", Proc. 6 Nat. Turbine Engine HCF Conf., Jacksonville, FL, Mar. 5-8, 2001.

8. V.V. Belozerov, et al., (1986), Met. Sci. Heat Treat., 28 , No. $7-8$, pp. 565-569. 
9. V.T. Stepurenko, et al., (1976), Protection of Metals, 12 , No. 4, pp. 386-389.

10. D.D. Papshev, Yu G. Golubev, (1972), Russian Engineering Journal, 52, No. 4, pp. 48-51.

11. M. Kh. Freid, et al., (1994), Protection of Metals, 20, No. 2, pp. 263-265.

12. L.M. Belkin, et al, (1984), Soviet Engineering Research, 4, No. 9, pp. 30-32.

13. L.M. Belkin, (1983), Soviet Materials Science, 19, No. 3, pp. 225-228.

14. M. Fattouh, et al., (1988), Wear, 127, pp. 123-137.

15. N.H. Loh, et al., (1989), Wear 129, No. 2, pp. 235243.

16. N.H. Loh, et al., (1993), Precision Engineering, 15, No. 2, pp. 100-105.

17. B. Kotiveerachari, R.L. Murty, (1985), International Journal of Production Research, 23, No. 3, pp. 499-521.

18. D.A. Hills, et al., (1979), Proc. Int'l Conference Wear of Materials, ASME, New York, NY, pp. 396402.

19. S. Braham, J. Frelat, (1993), Proc. Computer Methods and Exp. Meas. for Surface Treatment Effects, Computational Mechanics Publications, Southampton, U.K., pp. 255-264.

20. W. Zinn and B. Scholtes, "Mechanical Surface Treatments of Lightweight Materials - Effects on Fatigue Strength and Near-Surface Microstructures," Journal of Materials Engineering and Performance, Volume 8(2), April 1999 , pp. 145-151.

21. I. Altenberger, et.al., "Cyclic Deformation and Near Surface Microstructures of Shot Peened or Deep Rolled Austenitic Stainless Steel AISI 304," Materials Science and Engineering, A264, 1999, pp. 1-16.

22. A. Drechsler, et.al., "Mechanical Surface Treatments of Ti-10V-2Fe-3Al for Improved Fatigue Resistance", Materials Science and Engineering, A243, 1998, pp. 217-220.

23. Hilley, M.E. ed.,(1971), Residual Stress Measurement by X-Ray Diffraction, $S A E$ J784a, (Warrendale, PA: Society of Auto. Eng.).

24. Noyan, I.C. and Cohen, J.B., (1987) Residual Stress Measurement by Diffraction and Interoretation, (New York, NY: Springer-Verlag).

25. Cullity, B.D., (1978) Elements of X-ray Diffraction, 2nd ed., (Reading, MA: Addison-Wesley), pp. 447-476.

26. Prevéy, P.S., (1986), "X-Ray Diffraction Residual Stress Techniques," Metals Handbook, 10, (Metals Park, OH: ASM), pp 380-392.

27. Koistinen, D.P. and Marburger, R.E., (1964), Transactions of the ASM, 67.
28. Moore, M.G. and Evans, W.P., (1958) "Mathematical Correction for Stress in Removed Layers in X-Ray Diffraction Residual Stress Analysis," SAE Transactions, 66, pp. 340-345

29. Prevéy, P.S., (1977), "A Method of Determining Elastic Properties of Alloys in Selected Crystallographic Directions for X-Ray Diffraction Residual Stress Measurement," Adv. In XRay Analysis, 20, (New York, NY: Plenum Press, 1977), pp 345-354.

30. Prevéy, P.S., (1986) "The Use of Pearson VII Functions in XRay Diffraction Residual Stress Measurement," Adv. in X-Ray Analysis, 29, (New York, NY: Plenum Press), pp 103-112.

31. Prevéy, P.S., (1987), "The Measurement of Residual Stress and Cold Work Distributions in Nickel Base Alloys," Residual Stress in Design. Process and Material Selection, (Metals Park, OH: ASM). 